able that second response teams concerned in the management of trapped casualties and mass casualty incidents should carry one. The delivery of trauma care in the United Kingdom is currently under review, and the combination of pulse oximetry and trauma scoring at the roadside and later in the accident and emergency department should allow assessment of the effectiveness of immediate care to be made.

I thank Ohmeda and MAGPAS for their support in this study, Dr N A Silverston and Mr B B Milstein for their help in presenting the results, and Miss Nicola Townley for the photograph.
2 Champion HR, Sacco WJ, Carnazzoj AJ. The trauma score. Cin Care Med 1981;9:672-6

3 Silverston P. The PuLA: a new frontline airway? gournal of the British Asssociation of Immediate Care 1989;12:8-10.

Silverson P. The MAST suit Ambulane fow

+ Silverston P. The MAST sult. Ambulance Fourmal 1980;10:153-60.
5 Zorab JSM. Who needs pulse oximetry? Br Med F 1988;296:658-9.

6 Mihm FG. Halperin BD. Non-invasive detection of profound arterial desatur tion using a pulse oximetry device. Anesthesiologv 1985;62:85-7

7 Yelderman M, New W. Evaluation of pulse oximetry. Anesthesiology 1983;59: $349-52$.

8 Galdun J, Dunmire S, Caplan RM, Heler MB. Accuracy of transcutaneous, transconjunctival and pulse oximetry during air and ground transport with induced hrpoxia and hyperoxia. Ann Emerg Med 1988;17:188.

9 McGuire TJ, Pointer JE. Evaluation of a pulse oximeter in the pre-hospital setting Ann Emerg Med 1988:17:188.

10 Teasedale Gi Jennell B. Assessment of coma and impaired consciousness: a practical sale. Lancet 1974;ii:81.

\title{
HIV viral sequences in seronegative people at risk detected by in situ hybridisation and polymerase chain reaction
}

\author{
M Pezzella, P Rossi, V Lombardi, V Gemelli, R Mariani Costantini, M Mirolo, C Fundaro, \\ $\mathrm{V}$ Moschese, $\mathrm{H}$ Wigzell
}

\section{Abstract}

A study was conducted to assess the occurrence of latent infection with the human immunodeficiency virus (HIV) among seronegative people at high risk of infection. The presence of HIV genomes was analysed by molecular techniques in two seronegative children born to mothers infected with HIV and in three regular sexual partners of seropositive drug addicts. The adults were selected from a seronegative cohort at high risk of infection because of their sexual contacts and the children selected because of impaired growth. HIV retroviral sequences were detected in four of the five subjects directly at the cellular level by in situ hybridisation in peripheral blood mononuclear cells. HIV genomic sequences were confirmed by in vitro amplification of viral DNA with the polymerase chain reaction technique.

The existence of a latent viral infection state in these seronegative subjects indicates the unreliability of standard serological analysis in people who have been in regular contact with infected patients.

\section{Introduction}

After infection with the human immunodeficiency virus (HIV) viral genetic information becomes integrated in the genome of infected cells.' Epidemiological and clinical observations support the hypothesis that the virus may establish a latent infectious state characterised by low viral expression and the absence of a detectable specific antibody response..$^{2}$ Moreover, isolation of the virus by coculture techniques in seronegative subjects at risk $^{+}$suggests that serological analysis is not fully predictive of the infectious state and that infected seronegative people may be a potential source of uncontrolled spread of the virus. Recently high resolution molecular techniques have been described that allow the identification of viral genomes even if only a few copies of integrated or non-integrated viral DNA are present. In situ hybridisation with DNA or RNA (ribonucleic acid) probes gives qualitative information and accurately reflects the distribution of HIV viral genomes at the single cell level. ${ }^{5}$ The polymerase chain reaction technique, a new and sensitive method of gene amplification, allows the selective enrichment of a specific DNA sequence by a factor of $10^{6}$. These techniques might be of particular value in detecting HIV viral sequences when numbers of copies of cloning DNA (cDNA) and RNA per cell are very low.

We report using DNA-DNA, DNA-RNA, and RNA-RNA in situ hybridisation and polymerase chain reactions to identify HIV DNA and RNA in peripheral blood mononuclear cells from seronegative subjects at risk of infection-namely, children born to infected mothers and regular sexual partners of people infected with HIV.

\section{Patients and methods}

The study sample consisted of $(a)$ two seronegative women who were regular sexual partners of men infected with HIV (Centers for Disease Control group 3 and 2$) ;(b)$ a seronegative bisexual man who in the past two years had had sexual intercourse with infected partners; and $(c)$ two seronegative children aged 18 and 24 months born to asymptomatic seropositive mothers. The adult sample was collected from among a cohort of partners of people at risk attending the outpatient clinic of the National Centre for Blood Transfusion, Rome. This particular group was selected on the basis of the frequency of unprotected sexual contact with infected drug addicts. The two children were selected from a group of seronegative infants born to infected mothers and who had a history of impaired growth. All subjects were tested for specific serum antibodies to HIV by a commercial enzyme linked immunosorbent assay (ELISA) (ELAVIA; Pasteur) and by western blot analysis (Pasteur). Analysis of free antigen in the serum by an antigen capture assay (Abbott) was also performed. Immunological investigations included total T cell count and CD4 and CD8 phenotyping with commercial monoclonal antibodies in a fluorescence activated cell sorter (Becton Dickinson). All the subjects were enrolled for clinical and laboratory follow up and were monitored for more than one year.

\section{DNA-DNA AND DNA-RNA IN SITU HYBRIDISATION}

Heparinised peripheral blood samples were centrifuged over a Ficoll-Hypaque density gradient (Pharmacia, Sweden). Mononuclear cells collected at the interface were rinsed twice in Roswell Park Memorial Institute 1640 medium (Flow Laboratories) 
and resuspended at a concentration not exceeding $1 \times 10^{4} / 1$. Samples of the cell suspensions $(100 \mu \mathrm{l})$ were centrifuged on to precleaned microscope glass slides, dried in air, and fixed by immersion in acetone for five minutes. Preparations were stored at $-20^{\circ} \mathrm{C}$ until used for hybridisation. H9 cells infected and not infected with HIV were used as positive and negative controls. For hybridisation three different probes were used: a pSP64 plasmid containing the $9 \mathrm{~kb}$ SstI-SstI viral insert from the lambda HIV type I (HIV-I) BHlO recombinant clone $\mathrm{e}^{\mathrm{x}}$; the whole hepatitis $\mathrm{B}$ virus $(\mathrm{HBV})$ genome, near $3.3 \mathrm{~kb}$ long; purified from $\mathrm{pAOl}$ plasmid; and the pBR322 plasmid with no insert.

The hybridisation reaction was carried out as described $^{\times}$under conditions of high stringency established experimentally. Briefly, heat denatured probes were labelled by inserting an antigenic sulphone group into cytosine moieties (Chemiprobe; Orgenics). The cytocentrifuged peripheral blood mononuclear cells were heated for five minutes at $80^{\circ} \mathrm{C}$ in order to achieve both DNA denaturation and endogenous alkaline phosphatase activity. After heating the slides were treated with the hybridisation mixture $(2 \times$ sodium chloride trisodium citrate $50 \%$ deionised formamide, $10 \%$ dextran sulphate) containing the labelled probe. After overnight hybridisation at $37^{\circ} \mathrm{C}$ immunohistochemical visualisation was obtained by incubation with a monoclonal mouse antisulphone group antibody and then with an alkaline phosphatase conjugated antimouse antibody. The peripheral blood mononuclear cells were then further incubated with the chromogenic substrate nitroblue tetrazolium and mounted in glycerin. All the samples were tested with the HIV probe, the HBV probe, the pBR322 plasmid, or the hybridisation mixture lacking probe. The specificity of the hybridisation reaction was proved by positive and negative controls. The positive controls comprised (a) HIV infected $\mathrm{H} 9$ cell lines hybridised with the pSP64 plasmid containing the HIV viral insert and $(b)$ frozen sections of liver biopsy samples from hepatitis B surface and e antigen positive, HIV negative patients with chronic active hepatitis hybridised with the HBV probe. As negative controls we used (a) HIV infected $\mathrm{H} 9$ cells hybridised with the pBR322 plasmid lacking the viral insert and with the HBV probe and $(b) \mathrm{H} 9$ cells not infected with HIV.

\section{RNA-RNA IN SITU HYBRIDISATION}

For RNA-RNA in situ hybridisation we used pBH10-R3, a $9 \mathrm{~kb}$ human $\mathrm{T}$ cell lymphotropic virus type III insert of clone $\mathrm{BH} 10^{\prime}$ inserted $3^{\prime}$ to $5^{\prime}$ in the transcription vector pSP64 (Promega Biotec, Madison, Wisconsin). A $2 \mu \mathrm{g}$ sample of $\mathrm{pBH} 10-\mathrm{R} 3 \mathrm{DNA}$ was transcribed by using the Amersham SP6 RNA polymerase transcription kit and $25 \mu \mathrm{mol}$ sulphur-35 labelled uridine triphosphate $(29.6 \mathrm{GBq} / \mu \mathrm{mol}$; Amersham, United Kingdom). After transcription the DNA template was removed by digestion with ribonuclease free deoxyribonuclease (Boehringer, Federal Republic of Germany) and the labelled probe maintained at $-70^{\circ} \mathrm{C}$ for a maximum of 10 days before hybridisation. Transcripts from the pSP64 plasmid with no insert were similarly prepared and used as negative control for each patient under the same conditions as employed for HIV transcripts. In addition, H9 cells infected and not infected with HIV were routinely used as positive and negative controls.

Peripheral blood mononuclear cells were centrifuged on to acid cleaned slides, rapidly fixed in cold absolute , ethanol $(30 \mathrm{~s})$, and transferred in $4 \%$ buffered paraformaldehyde ( $\mathrm{pH} \mathrm{7.4)}$ for 15 minutes. The slides were washed briefly in cold phosphate buffered saline, dehydrated in graded ethanol, and dried in air before hybridisation. RNA-RNA in situ hybridisation was performed as described. ${ }^{10}$ The slides were autoradio- graphed in lightproof boxes under Nuclear Track Emulsion type 2 (Eastman Kodak, New York) diluted $1 / 1$ with distilled water for six days at $4^{\circ} \mathrm{C}$. After development and fixation the slides were stained with haematoxylin and examined for the presence and distribution of silver grains under an oil immersion $100 \times$ apochromatic objective at a magnification of 400 . Dense clusters of grains concentrated above and around peripheral blood mononuciear cells and with the pattern observed in positive control $\mathrm{H} 9$ cells represented the hybridisation signal.

\section{POLYMERASE CHAIN REACTION}

Polymerase chain reactions were performed with peripheral blood mononuclear cells obtained as described. Cells at the interface were collected and washed in isotonic saline ( $10 \mathrm{mmol}$ trometamol (TRIS), 149 mmol sodium chloride; $\mathrm{pH} 8 \cdot 0$ ). After three washes the pellet was resuspended in the DNA extraction buffer at a cell concentration not exceeding $10^{10}$ cells/ 1 . The cells were then lysed by adding $0 \cdot 2 \%$ sodium dodecyl sulphate and incubated with protease $\mathrm{K} 500 \mathrm{mg} / \mathrm{l}$. DNA was then extracted twice with phenol-chloroform and once with chloroform alone and precipitated with ethanol. After centrifugation DNA was resuspended in $0 \cdot 1 \times$ sodium chloride trisodium citrate and digested with heat treated ribonuclease A $(50 \mathrm{mg} / \mathrm{l})$ for one hour at $37^{\circ} \mathrm{C}$. DNA extraction was repeated as above and the DNA precipitated with ethanol resuspended in sterile water. To estimate the DNA concentration agarose gel electrophoresis was then performed. DNA $(1 \mu \mathrm{g})$ was denatured at $95^{\circ} \mathrm{C}$ for one minute and annealed with two pairs of HIV specific oligonucleotides (SK68 and SK69, and $\mathrm{CO} 1$ and $\mathrm{CO} 2)^{\circ}$ at $55^{\circ} \mathrm{C}$ for two minutes. These nucleotides flank regions within the HIV env and LTR regions respectively and are complementary to antisense strands. Chain elongation occurred simultaneously with primer annealing and continued for a further three minutes at $37^{\circ} \mathrm{C}$ in the presence of 2.5 units of the heat stable DNA polymerase (Taq) from Thermus aquaticus and $400 \mu \mathrm{mol}$ of each deoxynucleotide triphosphate in the reaction mixture. Samples were alternately warmed and cooled through 30 six minute cycles. One tenth of the resultant amplified DNA was then resolved by $2 \%$ agarose gel electrophoresis.

\section{Results}

All subjects were seronegative based on results of ELISA, western blot analysis, and antigen capture assay. The CD4:CD8 ratios were normal in all cases.

DNA-DNA and DNA-RNA in situ hybridisationThe specificity of the hybridisation reaction was indicated by strong cytoplasmic granular staining as in the HIV infected $\mathrm{H} 9$ cell line after hybridisation with the pSP64 plasmid containing the HIV viral insert. Selected normal blood donors and the uninfected H9 cell line were consistently negative when tested with the two viral probes (that is, HIV and HBV), as were mononuclear cell preparations treated with hybridisation mixture lacking probes and with the pBR322 plasmid lacking a viral insert. A typical positive reaction after hybridisation with the pSP64 HIV probe was observed in four of the five seronegative subjects studied and in all the positive controls. Retroviral sequences were visualised in the cytoplasm of mononuclear cells as granular staining. In some cases nuclear positivity was also found. Figure 1 shows a typical positive reaction pattern, including an easily recognisable infected blood monocyte. In each HIV positive sample, however, only a minority of peripheral blood mononuclear cells $(0 \cdot 1-1 \cdot 0 \%)$ showed positive reactions. 
RNA-RNA in situ hybridisation-By using RNARNA in situ hybridisation, which specifically identifies peripheral blood mononuclear cells expressing viral RNA, we confirmed the above findings. Only one subject (case 2) showed no viral RNA (table). The positive hybridisation signal consisted of a dense clustering of silver grains on and around the cytoplasm of the infected cell (fig 2). Infected H9 cells were consistently strongly positive, whereas uninfected $\mathrm{H} 9$ cells were consistently negative. The proportion of peripheral blood mononuclear cells expressing HIV

HIV-I in seronegative subjects at risk. (Findings in one seropositive drug addict included for comparison)

\begin{tabular}{|c|c|c|c|c|c|}
\hline $\begin{array}{l}\text { Case } \\
\text { No }\end{array}$ & $\begin{array}{l}\text { Western } \\
\text { blot }\end{array}$ & Description & DNA-RNA & RNA-RNA & $\begin{array}{c}\text { Polymerase } \\
\text { chain } \\
\text { reaction }\end{array}$ \\
\hline 1 & Positive & $\begin{array}{l}\text { Intravenous } \\
\text { drug abuser }\end{array}$ & Positive & Positive & Positive \\
\hline 2 & Negative & Female partner & Positive & Negative & Positive \\
\hline 3 & Negative & Female partner & Positive & Positive & Positive \\
\hline 4 & Negative & Bisexual man & Positive & Positive & Positive \\
\hline 5 & Negative & Infant & Positive & Positive & Positive \\
\hline 6 & Negative & Infant & Negative & Negative & Negative \\
\hline
\end{tabular}

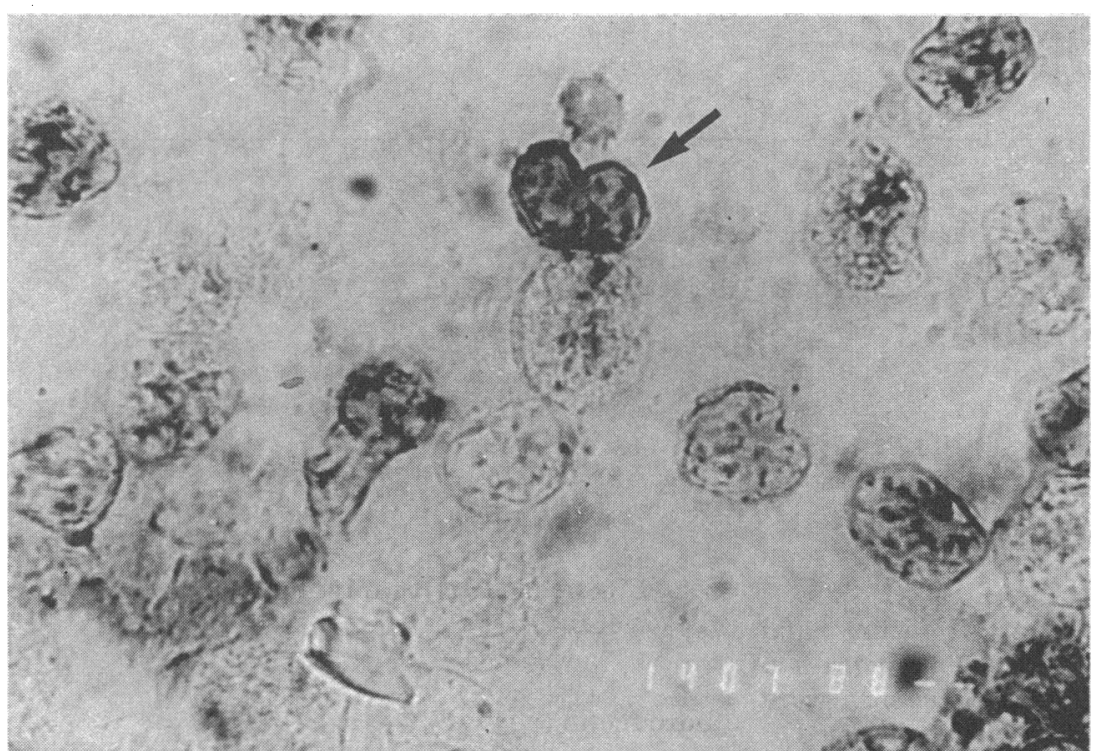

FIG $1-$ Detection of HIV DNA and RNA in peripheral blood mononuclear cells of seronegative subject at risk. DNA-DNA and DNA-RNA in situ hybridisation with SP64 plasmid containing $9 \mathrm{~kb}$ SstI-SstI viral insert from lambda HIV-I BHIO recombinant clone. Note granular staining of either cytoplasm or nucleus and presence of HIV positive monocyte (arrowed)

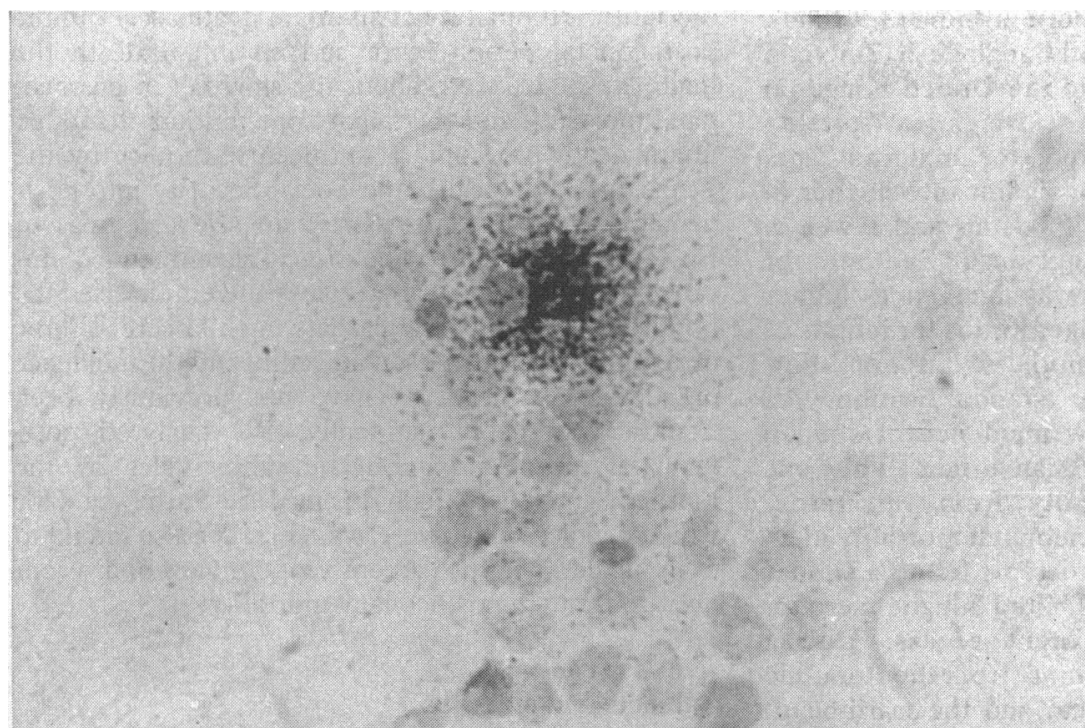

FIG 2-Detection of HIV RNA in peripheral blood mononuclear cells of seronegative subject at risk. RNA-RNA hybridisation with "S labelled $p B H 10-R 3$ transcript. Note dense labelling with silver grains of lymphocyte expressing HIV RNA. (Autoradiograph with haematoxylin counterstain)
RNA was lower than that found with the previous technique, being in the range of $1-2 / 10^{+}$cells.

Polymerase chain reaction-Four of the five seronegative subjects studied by means of the polymerase chain reaction technique showed a pronounced amplification band, which was further confirmed by Southern blot analysis using the SK70 oligonucleotide probe. All samples were amplified for 30 cycles.

\section{Discussion}

There is growing evidence of a prolonged asymptomatic carrier state in the absence of detectable serum antibodies in some people infected with HIV. ${ }^{11-1-1}$ These people represent a potential source of uncontrolled infection. We have analysed by three highly sensitive molecular techniques the possible occurrence of latent HIV infection in a small representative sample of seronegative subjects selected from very high risk groups - namely, regular sexual partners of seropositive drug addicts and children born to infected mothers. Of the five subjects studied, four were found to have viral DNA and RNA in the absence of a detectable antibody response.

The sexual partners of infected subjects showed positive reactions when their peripheral blood mononuclear cells were denaturated by heating before hybridisation, thus allowing the annealing of the viral DNA to the complementary DNA probe. One of these patients, however, was negative by RNA-RNA in situ hybridisation, which allowed annealing of the antisense probe only to complementary viral RNA. The lack of demonstrable viral RNA in this case may mean either that viral RNA was present but at too low a concentration to be detected by RNA-RNA hybridisation or that viral DNA occurred in the absence of active RNA transcription. Of the two children, one gave positive results with all three techniques, but results in the other were consistently negative with all the methods employed. These data confirm that some seronegative children delivered to infected mothers may have been infected during intrauterine life and may harbour viral genomes in their peripheral blood leucocytes. In a recent study of children at risk of the infection Amadori et al also found some who were positive for HIV DNA by polymerase chain reactions though seronegative or unable to form anti-HIV antibodies in vitro. ${ }^{13}$

Laure et al used the polymerase chain reaction technique in a study of 10 seronegative children and identified viral sequences in five. ${ }^{14}$ Their findings together with other reports of viral isolation in seronegative children at risk ${ }^{+}$emphasise the unreliability of serological tests for HIV in children born to seropositive mothers. The two children in our series investigated for latent infection were selected from an at risk group on the basis of failure to thrive. As in other immunodeficiency syndromes, failure to thrive is an early sign of immune response dysfunction and its occurrence must be carefully evaluated in seronegative children at risk of HIV. The high prevalence of positivity for viral sequences in our series may be attributed not only to the sensitivity of the techniques employed but also to the very high risk of infection that exists among unprotected close contacts of seropositive subjects.

Monocytes and macrophages containing HIV may have a role in inducing low grade infection in the absence of any substantial cytopathic effects. ${ }^{15}$ Many of our slide preparations for in situ hybridisation showed appreciable numbers of peripheral blood monocytes positive for HIV viral sequences. Analysis of the proportion of HIV positive monocytic versus T cells in seropositive and seronegative subjects might indicate whether an important difference exists between the 
two groups and whether this might account for the different immunological reactivities of the two populations.

In conclusion, we believe that in very high risk groups the combined use of in situ hybridisation and gene amplification by polymerase chain reactions is a necessary diagnostic tool for identifying asymptomatic seronegative carriers of HIV-I infection. Furthermore, viral isolation and characterisation will eventually explain whether the lack of immunological recognition in seronegative infected subjects at risk is due to the presence of peculiar viral isolates-for example, defective proviruses-or to a different viral cytotropism, or to both.

This work was supported by the Swedish Medical Research Council (MFR) (grant B89-16H-04A), the US Army Medical Research and Development Command (grant DAMD 17-86G-6039), and the Italian National Research Council (Cnr). PR was a visiting scientist at the Karolinska Institute. We thank Dr R C Gallo for providing BH 10 clones; Dr F Wong-Staal, of the National Institutes of Health, Bethesda, Maryland, for the pSP64 plasmid and pBH10-R3 DNA; and Dr A Buchbinder, National Institutes of Health, Bethesda, for the SK70 oligonucleotide probe.

1 Varmus H. Retroviruses. Science 1988;240:1+27-35

2 Fauci $\mathrm{AS}$. The human immunodeficiency virus: infectivity and mechanisms of pathogenesis. Science 1988;233:617-22.
3 Ranki A, Valle SI, Krohn M, et al. Long latency precedes overt seroconversion in sexually transmitted human-immunodeficiency-virus infection. Lancet 1987;ii:589-93.

+ Goetz DW, Hall SE, Harbizon RW, Reid MJ. Pediatric acquired immunodeficiency syndrome with negative human immunodeficiency virus antibody response by ELISA and western blot. Pediatrics 1988;81:356-9.

5 Hames BD, Higgins SJ. Nucleic acid hybridization. A practical approach. Washington, DC: IRL Press, 1985:179.

6 Ou CY, Kwok S, Mitchell SW, et al. DNA amplification for direct detection of HIV-1 1)NA of peripheral blood mononuclear cells. Science 1988;239:295-7.

7 Saiki RK, Gelfand DH, Stoffel S, et al. Primer-directed enzymatic amplification of DNA with a thermostable DNA polymerase. Science 1988;239: 487.91.

8 Pezzella M, Pezzella F, Gali $\mathrm{C}$, et al. In situ hybridization of human immunodeficiency virus (HTLV III) in cryostat sections of lymph nodes of lymphadenopathy syndrome patients. F Med Virol 1987;22:135-42.

9 Hahn BH, Shaw (FM, Anya SK, et al. Molecular cloning and characterization of the HTLV III virus associated with AIDS. Nature 1984;312:166-9.

10 Harper ME, Marselle LM, Gallo RC, Wong-Staal F. Detection of lymphocytes expressing human T-lymphotropic virus type III in lymph nodes in peripheral blood from infected individuals by in situ hybridization. Proc Nall Acad Sci L'SA 1986;83:772-6.

11 Curran JW, Jaffe HW, Hardy AM, el al. Epidemiology of human immunodeficiencr virus infection and AIDS in the United States. Science 1988:239: $610-6$

12 Loche M, Mach B. Identification of HIV-infected seronegative individuals by a direct diagnostic test based on hybridisation to amplified viral DNA. a direct diagnostic tes

13 Amadori A, De Rossi A, Giaquinto C, et al. In vitro production of human immunodeficiency virus specific antibody in children at risk of AIDS. Lancet
imadonation of human immunodeficic 1988 ;ii: $852-4$.

1t Laure F, Courgnaud $V$, Rouzioux $C$, et al. Detection of HIV-1 DNA in infants and children by means of the polymerase chain reaction. Lancet 1988;ii: $538-41$

15 Gartner S, Markovitz D, Markovitz DM, et al. The role of mononuclear phagocytes in HTLV III/LAV infection. Science 1986;233:215-9.

Accepted 9 fanuary 1989
Epidemiology and Public Health Research Unit, University of Surrey, Guildford, Surrey GU2 5XH

$\mathrm{R}$ Balarajan, $\mathrm{FFCM}$, director $\mathrm{V}$ Soni Raleigh, PHD, senior research fellow

\section{Medical Statistics} Division, Office of Population Censuses and Surveys, London WC2B 6JP

B Botting, BSC, statistician

Correspondence to: Dr Balarajan.

\title{
Sudden infant death syndrome and postneonatal mortality in immigrants in England and Wales
}

\author{
R Balarajan, V Soni Raleigh, B Botting
}

\section{Abstract}

To examine ethnic differences in postneonatal mortality and the incidence of sudden infant death in England and Wales during 1982-5 records were analysed, the mother's country of birth being used to determine ethnic group. Postneonatal mortality was highest in infants of mothers born in Pakistan $(6 \cdot 4 / 1000$ live births) followed by infants of mothers born in the Caribbean (4.5) and the United Kingdom and Republic of Ireland $(4 \cdot 1)$. Crude rates were lower in infants of mothers born in India (3.9/1000), east and west Africa (3.0), and Bangladesh (2.8) than in infants of mothers born in the United Kingdom despite less favourable birth weights. Mortality ratios standardised separately for maternal age, parity, and social class were significantly higher in infants of mothers born in Pakistan and lower in those of mothers born in Bangladesh. The ratio for infants of Caribbean mothers was significantly higher when adjusted for maternal age. Ratios for infants of Indian and east African mothers did not show significant differences after standardisation. An important finding was a low incidence of sudden infant death in infants of Asian origin. This was paralleled by lower mortality from respiratory causes. During $1975-85$ postneonatal mortality in all immigrant groups except Pakistanis fell to a similar or lower rate than that in the United Kingdom group; Pakistanis showed a persistent excess. During 1984-5 several immigrant groups (from the Republic of Ireland, India, west Africa, and the Caribbean) recorded an increase in postneonatal mortality.

Surveillance of postneonatal mortality among ethnic communities should be continued, and re- search is needed to identify the causes underlying the differences.

\section{Introduction}

Most of the fall in infant mortality since the 1970s has been due to a steady fall in neonatal mortality rather than postneonatal mortality.' During 1985-6 postneonatal mortality in fact increased from $3 \cdot 9 / 1000$ live births to $4 \cdot 3 / 1000$, leading to a rise in overall infant mortality. ${ }^{2}$ About $42 \%$ of all infant deaths occur in the postneonatal period, with sudden infant death the main cause. ${ }^{3}$ Concern about the slow fall in postneonatal mortality and the major contribution of sudden infant death prompted a multicentre inquiry by the Department of Health and Social Security into postneonatal deaths during 1976-9 in selected areas of England and Wales. ${ }^{+}$The study recommended improvements in health care services and emphasised the importance of educating parents in child care. Ethnic differences in postneonatal mortality and the incidence of sudden infant death have not previously been examined in detail nationally. We analysed postneonatal mortality in England and Wales by the mother's country of birth during 1982-5, the years for which detailed tables were available. We also intend to examine data for subsequent years in view of a recent upward trend in postneonatal mortality. ${ }^{2}$

\section{Subjects and methods}

Since 1975 the Office of Population Censuses and Surveys has linked records of births and deaths of infants under 1 year old. ${ }^{5}$ Data from these records were 